\title{
MATTERS
} ARISING

\section{Syndromic management of genital ulcer} disease-a critical appraisal

The letter by Kumar on syndromic management is fascinating. ${ }^{1}$ The WHO Technical Report Series 810, Geneva 1991 described the syndromic approach for the treatment of different sexually transmitted diseases in developing countries. In India, although there are more than 500 STD clinics, only 42 are functioning properly with adequate records of cases. Follow up of patients must always be based on records and hence follow up in most clinics in India is not possible.

With the advocacy of the syndromic approach to treatment of genital ulcer disease and discharge, cases are diagnosed on the basis of flow charts, without laboratory aid and are treated accordingly. This results in the provision of less information about HIV positive cases among unregistered patients. This will become a big socia problem because HIV positive cases remain unrecorded and become a source for the propagation of infection.

We would strongly recommend that the WHO make it mandatory that there should be proper record keeping and follow up of cases treated with the syndromic approach that have either genital ulcer disease or urethral discharge.

R BHARGAVA
D MATHUR
P BHARGAVA
Department of Dermatology,
STD and Leprosy,
SMS Medical College,
faipur 302004 ,
India

Address correspondence to: Dr R Bhargava, C-32, Peeyush Path, Bapu N agar, Jaipur 302 015, India.

1 Kumar B, Handa S, Dawn G. Syndromic management of genital ulcer disease-a critical appraisal. Genitourin Med 1995;71 197.

Should screening of genital infections be part of antenatal care in areas of high HIV prevalence?

The study by Leroy and colleagues ${ }^{1}$ provides further evidence of the association between the presence of sexually transmitted disease (STDs) and human immunodeficiency virus type-1 (HIV), supporting other previously published evidence of such an association, ${ }^{2}$ while a recent study by Grosskurth and colleagues has demonstrated how improved care-management of STDs will prevent transmission of HIV. ${ }^{4}$ Evidence of this association also exists in the province of Masvingo in southern Zimbabwe. During
1994 the clinic attendance rate of patients with STD symptoms in the predominantly rural provincial population was 187 per 1000 population aged $15-59$ years. An HIV sero-surveillance survey, conducted by Masvingo Provincial Medical Director's Department during the same year indicated a positivity rate amongst rural STD patient of $53.2 \% \quad(n=79,95 \%$ confidence limit $42 \cdot 2 \%-62 \cdot 2 \%$ ), while the overall positivity rate amongst rural antenatal clinic attenders was $18 \cdot 1 \%$ ( $n=282,95 \%$ confidence limit $13.5 \%-22 \cdot 7 \%$ ). In Masvingo town, the provincial capital (population 52,000, 4.2\% of the provincial total population), the 1994 clinic attendance rate of patients with STD symptoms was 413 per 1000 population aged 15-59 years. The HIV sero-surveillance survey carried out at one of the town's clinics indicated a positivity rate among STD patients of $75.4 \%$ ( $n=191,95 \%$ confidence limits $69 \cdot 2 \%-81 \cdot 6 \%$ ) while the positivity rate amongst the antenatal clinic attender was $35 \cdot 2 \%$ ( $n=293,95 \%$ confidence limits $29 \cdot 6 \%-40 \cdot 8 \%$ )

The clinic attendance rate of patients with STD symptoms has actually declined since 1991 , both in Masvingo town and in the province as a whole. The decline has also occurred in clinic attenders with STD symptoms as a proportion of all new clinic attenders aged more than 5 years, again both in Masvingo town (from $44.7 \%$ to $33.0 \%$ ) and in the province (from $12.9 \%$ to $6.1 \%$ ). This might suggest that for whatever reason, a behavioural change is now taking place in this area of southern Africa. Intervention efforts to change behaviour have recently been associated with a fall in the prevalence of HIV-1 in young males in rural Uganda. Further surveys of HIV prevalence rates are planned in Masvingo province and in time should provide valuable information regarding the spread of this particular STD. None the less, effective STD case management is obviously an important aspect of any HIV prevention strategy. Resources need therefore to be directed towards ensuring that all sexually active members of any population are able to access effective and acceptable STD care services.

$$
\begin{array}{r}
\text { M L'HERMINEZ } \\
\text { R L'HERMINEZ } \\
\text { Provincial Medical Director's Office, } \\
\text { Masvingo, Zimbabwe } \\
\text { Public Health Directorate } \\
\text { I HOLTBY } \\
\text { Public Health Directorate, } \\
\text { Poole Hospital, } \\
\text { Nunthorpe, Middlesborough, } \\
T S 7 \text { ONF } \\
\text { UK }
\end{array}
$$

Address correspondence to: D I Holtby

1 Leroy V, De Clercq A, Ladner J, Bogaerts J, Van de Perre P, Dabis F. Should screenin of genital infections be part of antenatal care in areas of high HIV prevalence? A prospective cohort study from Kigali, Rwanda, 1992-93. Genitourin Med 1995;71:207-11.

2 Newell J, Senkoro K, Mosha F, et al. A population-based study of syphilis and sexually transmitted disease syndromes in northwestern Tanzania. 2 Risk factors and health seeking behaviour. Genitourin Med 1993;69: $421-6$.

3 Laga M, Alary M, Nzili N, Manoka AT, et al Condom promotion, STD treatment leading to a declining incidence of HIV-1 infection in female Zairean sex workers. Lancet 1994; 344:246-8

4 Grosskurth H, Mosha F, Todd J, et al; Impact of improved treatment of sexually transmitted diseases on HIV infection in rural Tanzania: randomised controlled trial Lancet 1995;346:530-6.

5 Mulder D, Nunn A, Kamali A, KengeyaKayondo J; Decreasing HIV-1 seroprevalence in young adults in a rural Ugandan cohort. $B M \mathcal{F}$ 1995;311:833-6.

\section{BOOK REVIEWS}

All titles reviewed here are available from the BMF Bookshop, PO Box 295, London WC1H 9TE. Prices include postage in the UK and for members of the British Forces Overseas, but overseas customers should add $15 \%$ to the value of the order for postage and packing. Payment can be made by cheque in sterling drawn on a UK bank, or by credit card (Mastercard, Visa, or American Express) stating card number, expiry date, and full name. Contraception Today. By J GUILLEBAUD.
London: Martin Dunitz. ( $(9.95)$ ISBN 1 85317-250-2

A reduction in the number of unwanted pregnancies and the incidence of sexually transmitted diseases are key objectives in strategic documents such as the Health of the Nation (UK). Traditionally in the domain of separate disciplines, these issues are inextricably linked.

A significant proportion of female GUM clinic clients may be using no contraception or using it inadequately. The chosen method has implications for the risk of genital infection and its side-effects may complicate the presented symptomatology. Current training programmes acknowledge that genitourinary physicians and family planning doctors have much to offer each others' speciality.

Contraception Today makes a valuable conto the education of all workers in the field of sexual health. Subtitled $A$ Pocketbook for General Practitioners it is packed with information of value and interest to those in GU medicine at any stage in their careers.

The author, Professor John Guillebaud is Medical Director of the Margaret Pyke Centre for Study and Training in Family Planning, London. He has lectured extensively at home and abroad and enjoys an international reputation as an academic, a practitioner and teacher. His book demontrates considerable clinical experience and critical scientific appraisal.

Each chapter discusses a different method of contraception with its risks and benefits, side effects, practicalities of use and management of problems. Other aspects of sexual health, particularly STDs, accompany the central theme of contraception. It is heartening to read the advice that-" "no opportunity should be missed to advise sexually active women of all ages about how they may minimise their risk of infection from sexually transmitted diseases". Barrier methods and education in their correct use are highly valued for their role in STD prevention. The text is thoroughly up-to-date and presented in a lucid accessible style. Coloured insets are used liberally to highlight key information. Clear, simple diagrams of management guidelines make it an excellent reference for day-to-day problems.

Much space is given to the combined oral contraceptive which continues to be attacked by the popular press thus generating concern among users. Of particular use 
to GU physicians are the sections on breakthrough bleeding and the effect of concurrent use of antibiotics. Although not fully referenced, important studies are cited in discussion of controversial issues. A suggested reading list offers fuller coverage. The publication of this book did however predate the October 1995 Committee on Safety of Medicines Guidelines on combined oral contraception.

Chapters include discussion of progestogen-only methods-oral, injectable and implants, post-coital contraception, barrier methods and new in this, the second edition, the intra-uterine contraceptive. John Guillebaud dispels the myths about the IUD with regard to ectopic pregnancies and pelvic inflammatory disease. He predicts a "truly dramatic 'come-back' for IUDs in the near future". The importance of pre-existing carriage of STDs is emphasised. A protocol for infection screening of prospective IUD users is presented which includes a low threshold for referral to GU clinics. The new levonorgestrel releasing IUD is praised; with its "unsurpassed efficacy" and reduction in the frequency of clinical PID it will "re-write the textbooks about IUDs".

Contraception Today abridges a considerable body of literature and is highly recommended for those wanting a concise update on current contraceptive practice.

LYNNE GILBERT

HIV infection in children, a guide to practical management. Edited by J MOK and $M$ NEWELL. Cambridge. Cambridge University Press. 1995. (Pp. 313; £40) ISBN 0521454212

This is an excellent book for those caring for HIV infected children in the developed world. Management of these children is extremely complex, requiring multidisciplinary input and is evolving constantly. The contents of the book cover the important areas in which health carers need to be informed. The chapters have been written by a team of international contributors with considerable expertise. It gives details of experience and management strategies from both European and North American perspectives. The information is up to date, well referenced and presented in very readable chapters. This book will be useful to all those involved in health care of HIV infected children.

M D S WALTERS

\section{NOTICES}

\section{BSCCP. Basic Colposcopy Course}

4-5 July 1996 and 28-29 November 1996. Birmingham. Contact Mrs E Dollery, 3rd Floor, Birmingham Maternity Hospital, Birmingham B15 2TG, Telephone 0121 6074716

United States FDA Medical Device Update: Design Controls, GMP Requirements and Marketing Clearance

Charles de Gaulle Hilton, Paris, France. 20-23 May 1996.

An international meeting on FDA GMP and marketing regulations including the proposed new GMP requirements and how to comply with them. All three days will be presented by FDA's CDRH with a presentation by the European Commission. Sponsored by the French Government.

For further information please contact: Sharon Goff, Advanstar Communications, Advanstar House, Park West, Sealand Road, Chester CH1 4RN, UK. Tel: + 44 (0) 1244 378 888. Fax: + 44 (0) 1244370011 .

\section{A Practical Course in Laser Appli-} cations for Cutaneous Lesions

18-20 July 1996. Singapore. Contact Mrs A Chew, 1 Mandalay Road, Singapore 1130, Telephone (65) 3508405

European Regional IUVDT Conference on STDs and Eurogin Conference on Herpes Viruses and Genital Pathology. Paris, France, 24-25 October 1996.

Address enquiries to: Congress Secretariat: BAXON Communication, 69/73 Avenue du Général Leclerc, BP 304-92102 Boulogne, France.
18-20 April

21-25 April

5-8 May

9-11 May 1996

12-16 May 1996

14-17 May

10-13 June

3-6 July

7-12 July 1996

11-14 Sept 1996

15-18 September

18-20 September

13-17 Oct 1996

17-18 Oct 1996

23-25 Oct 1996

3-7 Nov 1996

1-5 Dec 1996
British Society for Colposcopy and Cervical Pathology. Stoke-on-Trent, UK.

Viral hepatitis and liver disease. Rome, Italy.

Society for Clinical Trials. USA.

Spring Meeting of the Medical Society for the Study of Venereal Diseases, Edinburgh, UK

9th World Congress on Cervical Pathology and Colposcopy, Sydney, Australia

First European Congress of Chemotherapy. Glasgow, Scotland.

7th International Congress for Infectious Diseases. Hong Kong. Fifth International Drug Resistance Workshop. Whistler, Canada.

XI International Conference on AIDS, Vancouver, Canada

Third European Chlamydia Meeting, Vienna, Austria

Interscience Conference on Antimicrobial Agents and Chemotherapy (ICAAC). New Orleans, USA.

Society for Social Medicine. Dundee, UK.

5th European Academy of Dermatology and Venereology, Lisbon, Portugal

6th European Course on HPV-associated Pathology, Amsterdam

European Regional Meeting of the International Union Against the Venereal Diseases and the Treponematoses, Paris, France

3rd International Congress on Drug Therapy in HIV Infection, Birmingham, UK

International Papillomavirus Workshop, Queensland, Australia 